\title{
The Stabilization of Cartilage Properties in the Cartilage-forming Mesenchyme of the Embryonic Chick Limb ${ }^{1,2,3}$
}

\author{
ROBERT L. SEARLS AND MARTHA Y. JANNERS \\ Department of Biology, Temple University, Philadelphia, Pa. 19122, and \\ University of Michigan, Dearborn Campus, Dearborn, Mich. 48128
}

\begin{abstract}
Experiments have been done to determine the time in the development of the embryonic chick limb when the cells in the cartilage-forming area become "stabilized." The particular criterion for stability used in this work was the ability of the cells to resist the infiuences in the limb which cause some limb mesenchyme cells to form cartilage and other limb mesenchyme cells to form soft tissue. Blocks of cartilage-forming mesenchyme were transplanted from the cartilage-forming area of one limb to the prospective soft tissue area of a second limb. The host limb was permitted to develop for 48 hours, and then examined to determine if the implanted cells had formed cartilage outside of the normal cartilage pattern of the host limb. The embryos used as a source of the implanted blocks varied in stage from stage 22 to stage 27, the hosts also varied in stage from stage 22 to stage 27 .

It was found that a block of cartilage-forming mesenchyme generally would conform with the host limb pattern if the donor was stage 24 or younger and the host was stage 24 or younger. A block of cartilage-forming mesenchyme generally did not conform with the host limb pattern if the donor was stage 25 or older whatever the stage of the host. We conclude that the cartilage-forming cells become stabilized by this criterion between stage 24 and stage 25 .
\end{abstract}

It has been observed that the cartilageforming cells of the embryonic chick limb remain labile until surprisingly late in limb development (Searls, '67). The experiments described in that paper had been done to investigate the role of cell migration in the development of the limb. Blocks of mesoderm from the cartilage-forming areas of stage 23 (Hamburger and Hamilton, '51) and stage 24 embryonic chick limbs were implanted into the dorsal surface of the right wings of embryos growing in ovo. After a period of further development, the host limbs were examined to discover the fate of the implanted cells. No evidence of cell migration out of or through the implanted blocks could be detected. It was further observed that the implanted blocks became integrated into the host limb and that the implanted cells differentiated according to the host pattern, forming cartilage in the cartilageforming area of the host limb and soft tissue in the soft tissue area of the host limb.

This lability of cartilage-forming mesenchyme from stage 24 limb buds was unexpected because extracellular metachromatic material appears in the cartilage- forming area of the limb during stage 25. It has generally been observed that cells become stabilized somewhat before they begin to demonstrate the overt signs of a particular differentiation (Grobstein, '64). Cartilage cells have been demonstrated to be capable of preserving their special properties in cell culture (Coon, '66; Cahn and Lasher, '67; Abbott and Holtzer, '68) and during limb regeneration (Patrick and Briggs, '64; Steen, '68; Namenworth, '68).

Experiments have been done to determine if a block of cartilage-forming cells from the limb of a chick embryo ever becomes so stabilized as cartilage that the cells will not respond to the influences in the limb that caused some of the limb mesenchyme cells to become cartilage and other limb mesenchyme cells to become soft tissue; and, if they do become so

\footnotetext{
1 This research was supported in part by N.S.F. research grant G.B. 4846 .

2 This is the fifth paper in a series on the differ2This is the fifth paper in a series on the differ-
entiation of cartilage in the limb bud of the embryonic chick. Some of the research reported in this paper was performed at the Biology Department; University of Virginia, Charlottesville, Virginia, and has appeared in preliminary form (Am. Zool., 7 ('67)).

3 Requests for information concerning this paper hould be Biology, Temple University, Philadelphia, Pa.
} 
stabilized, the stage in embryonic development when this stabilization occurs. Evidence was also obtained concerning whether the ability of the host limb to control the differentiation of ectopically implanted blocks of cells changes during limb development.

Blocks of cartilage-forming mesoderm were obtained from the limbs of embryos at each stage from stage 22 to stage 27 . These blocks were inserted into the right wing buds of embryos growing in ovo that were at each stage from stage 22 to stage 27. After 48 hours of further development, the host wings were examined to determine whether extracellular metachromatic material was to be found in the implanted blocks outside of the normal cartilage pattern of the host limb.

It has been found that a block of limb cartilage-forming mesenchyme that has been obtained from the limb of an embryo stage 24 or younger will usually conform with the host limb pattern if the host is stage 24 or younger. A block of limb cartilage-forming mesenchyme which has been obtained from the limb of a stage 25 or older embryo will usually form ectopic cartilage in host limbs of embryos of any stage from stage 22 to stage 27 . We conclude that blocks of limb cartilage-forming mesenchyme become stabilized as cartilage by this criterion between stage 24 and stage 25. However, when a block of limb cartilage-forming mesenchyme from a stage 23 or stage 24 embryo was implanted into the limb of a stage 25 or older host embryo, the implanted cells formed ectopic cartilage with an increased frequency. This result suggests that the host limbs lose some, but not all, of their ability to control the differentiation of implanted cells between stage 24 and stage 25. Further, this result suggests that cartilage-forming cells from the limbs of stage 23 and stage 24 embryos are already strongly inclined toward the formation of cartilage.

\section{MATERIALS AND METHODS}

The procedures used in these experiments were identical with those used previously (Searls, '67). Windows were prepared in the shells of White Cornish Cross eggs (Brown Cornish male X Arbor Acres
White Rock female) after two days of incubation at $37^{\circ}$ (Zwilling, '59). Incubation was continued at $37^{\circ}$ until the eggs had reached the desired stage of development.

Donor embryos were labeled by the injection of tritiated thymidine $(10 \mu \mathrm{c}$; New England Nuclear Corp.; greater than $10 \mathrm{C}$ per $\mathrm{mM}$; diluted with Tyrode's solution to $100 \mu \mathrm{c}$ per $\mathrm{ml}$ ) into the yolk sac through a hole drilled in the large end of the egg. The injection was always at least ten hours before the embryo had reached the desired stage, and never later than stage 22. It has been observed that some of the cells in the chondrogenic area will not become labeled if the injection occurs any later than that stage (Janners, '68). When a donor embryo had reached the stage desired for a particular experiment, it was transferred into Tyrode's solution at room temperature. The limb buds were cut from the embryo and the cartilage-forming areas were isolated with cataract knives as described previously (Searls, '67). The cartilage-forming areas were then cut into small blocks 0.1 to $0.2 \mathrm{~mm}$ on the longest side. In some experiments leg and wing buds were mixed, in other experiments only the leg buds were used since the cartilage-forming areas from the leg buds were somewhat easier to obtain free of other mesoderm.

Other eggs were incubated until the embryos had reached an appropriate stage for use as hosts. The window in the shell was opened. Working through the window, a pocket was made with a tungsten needle in the dorsal surface of the right wing bud in the area of the prospective humerus (Saunders, '48). A block of labeled mesoderm was inserted into this pocket. No attempt was made to control the orientation of the implanted block or the exact position of the implanted block in the host limb. The window was sealed with Scotch tape and incubation was continued at $37^{\circ}$ for a further 48 hours.

The host limbs were fixed in Bouin's fluid, embedded in paraffin, and sectioned at $5 \mu$. The paraffin was removed with xylene, the sections were hydrated through a graded series of alcohols, and kept in distilled water. The slides were dipped in Kodak NTB-3 photographic emulsion while wet. After the emulsion had dried, the 
slides were stored in the dark over Drierite at $4^{\circ}$ for three months. The emulsion was developed in D-19 (Caro and Tubergen, '62). The sections were stained with hematein by a double bath technique (Searls, '67). When there was question as to the presence of cartilage, the sections were destained with acid-alcohol and stained with toluidine blue.

\section{RESULTS}

Tabulation of the results and description of the criteria used

Table 1 presents a summary of all of the operations done in this laboratory in which the donor was labeled with tritiated thymidine and the host was allowed to develop for at least 48 hours after the operation. Some of the operations listed in table 1 were listed in a previous publication (Searls, '67). Table 1 does not include any of the operations in the previous publication in which the donor had been labeled with S-35 sulfate. The rather heavy non-nuclear labeling in most of those implants masked any metachromatic material which might have been present.

The criterion used in this work for "stability of differentiation" was the appearance of cartilage within the implanted block of tissue which did not appear to be part of the normal cartilage pattern of the host limb. Decision as to whether the cartilage observed in an implanted block was part of the normal cartilage of the host limb was made by inspection. None of the host limbs was reconstructed.

The results have been described entirely in terms of cartilage vs. non-cartilage. Cells surrounded by metachromatic material after a total of 5 to 7 days of development have been called cartilage cells, cells not surrounded by metachromatic material at that time have been called soft tissue. Multinucleate straps are observed in the limb after 6 to 7 days of development, but are still so poorly formed at the end of eight days of development that it is difficult to determine if a particular labeled cell is within a strap. This difficulty in recognizing soft tissue cells has prevented further analysis of the implant-derived cells which become soft tissue.

A summary of the results, in terms of the number of implants that formed ectopic cartilage, is presented in table 2.

\section{Operations in which the donors were stage 24 or younger, hosts stage 24 or younger}

It had been observed previously (Searls, '67) that blocks of mesoderm obtained from the cartilage-forming area of stage 22 to stage 24 limbs when implanted into stage 24 or younger host limbs usually were incorporated into the host limb and differentiated in accordance with the host pattern. Further operations of this kind have been done. All together, in the new experiments and the old experiments, 70 implants obtained from 13 different donor embryos have been examined. Of the 70 implants, only $5(7 \%)$ appeared to give ectopic cartilage.

By stage 24, the chondrogenic area is fully developed. Metachromatic material appears in the limb during stage 25. Fifteen operations, using three different donor embryos, were done in which both the donor and the host were stage 24. Ectopic cartilage was found in three $(20 \%)$ of these implants.

The three implants which developed ectopic cartilage were from a single donor

TABLE 1

Summary of the operations done in this laboratory in which the donor was labeled with tritiated thymidine and the host was allowed to develop for at least 48 hours after the operation

\begin{tabular}{ccccccc}
\hline $\begin{array}{c}\text { Stage of } \\
\text { donor }\end{array}$ & Number & \multicolumn{5}{c}{ Stage of host } \\
\cline { 3 - 7 } & 21 and 22 & 23 & 24 & 25 & 26 and 27 \\
\hline 22 & 36 & 21 & 2 & 3 & 10 & \\
23 & 36 & 4 & 3 & 14 & 13 & 2 \\
24 & 41 & 2 & 6 & 15 & 14 & 4 \\
25 & 33 & & 4 & 12 & 14 & 3 \\
26 and 27 & 45 & 1 & 7 & 8 & 7 & 22 \\
\hline
\end{tabular}


TABLE 2

A summary of the results giving the number of operations at each stage and the number which formed ectopic cartilage

\begin{tabular}{|c|c|c|c|c|c|c|c|}
\hline \multirow[b]{2}{*}{$\begin{array}{l}\text { Donor } \\
\text { stage }\end{array}$} & \multirow{2}{*}{$\begin{array}{l}\text { Host } \\
\text { stage }\end{array}$} & \multicolumn{3}{|c|}{$22,23,24$} & \multicolumn{3}{|c|}{$25,26,27$} \\
\hline & & $\begin{array}{c}\text { Total } \\
\text { number }\end{array}$ & $\begin{array}{l}\text { Number } \\
\text { ectopic } \\
\text { cartilage }\end{array}$ & $\begin{array}{l}\text { Ectopic } \\
\text { cartilage }\end{array}$ & $\begin{array}{c}\text { Total } \\
\text { number }\end{array}$ & $\begin{array}{l}\text { Number } \\
\text { ectopic } \\
\text { cartilage }\end{array}$ & $\begin{array}{l}\text { Ectopic } \\
\text { cartilage }\end{array}$ \\
\hline & & & & $\%$ & & & $\%$ \\
\hline 22 & & 26 & 0 & 0 & 10 & 0 & 0 \\
\hline 23 & & 21 & 2 & 10 & 15 & 4 & 27 \\
\hline 24 & & 23 & 3 & 13 & 18 & 15 & 83 \\
\hline 25 & & 16 & 15 & 94 & 17 & 15 & 88 \\
\hline 26 and 27 & & 16 & 15 & 94 & 29 & 24 & 83 \\
\hline
\end{tabular}

embryo. The right wing of this embryo measured $1.2 \mathrm{~mm}$ along the body wall and $1.6 \mathrm{~mm}$ from the body wall to the apex of the wing. An embryo whose right wing was any larger than this would be considered to be a stage 25 embryo in this laboratory. All of the implants from this particular donor were obtained from the leg buds. Ten operations using this donor and stage 24 host embryos survived for 48 hours. In seven of the ten implants (70\%), the implanted cells differentiated in accordance with the pattern of the host wing (fig. 1). Those cells that had come to lie in the cartilage-forming area of the host wing formed cartilage, those cells which had come to lie in the soft tissue area of the host wing formed soft tissue. This result was observed in 65 of the 70 implants in this group.

In the other three implants from that donor, the boundaries of the host cartilage appeared to be distorted by the cells of the implant (fig. 2). Cartilage extended into the implant as if the control exerted by the host limb was not sufficient to prevent those implant cells contiguous with the cartilage-forming area of the host from forming cartilage. This was the result obtained with 5 of the 70 implants in this group. It is possible that the cartilage in these limbs is normal, the appearance of distortion may be due to the plane of section. The number of cases of this kind was small enough that they did not distort the conclusions, it did not appear profitable to reconstruct these limbs to determine if the cartilage pattern had in fact been distorted. In all of these implants, implant cells some distance from the host cartilageforming area formed soft tissue.
Operations in which the donors were stage 25 or older, hosts stage 25 or older

These experiments were continued with older donors and older hosts in an attempt to discover when, during limb development, the cells of the cartilage-forming area of the limb lose the ability to conform with an ectopic site in a host limb. Fortysix implants, obtained from 13 different donor embryos stage 25, stage 26 and stage 27 and implanted into hosts of the same stages, were examined. Of the 46 implants, $39(85 \%)$ developed cartilage which was clearly separate from the cartilage of the host limb.

Cells in the cartilage-forming area of the limb are first surrounded by faint wisps of metachromatic material at stage 25 . In 14 operations, using five different donor embryos, both the donor and the host were stage 25. Ectopic cartilage was found in $12(86 \%)$ of these implants (fig. 3). In almost every case, the ectopic cartilage which formed was clearly separate from the cartilage of the host limb. The two implants that failed to produce ectopic cartilage were obtained from the same donor embryo. Seven other implants from that donor produced ectopic cartilage. One of the two implants that failed to produce ectopic cartilage produced both cartilage and soft tissue in the host pattern. The other was entirely within the soft tissue area of the host limb and produced only soft tissue.

\section{Operations in which the donor was stage 25 or older, hosts stage 24 or younger}

To discover if the cells of the cartilageforming area of the stage 25 limb had be- 
come stabilized as cartilage, those cells had to be tested under the conditions which caused the cells from the cartilage-forming area of the stage $24 \mathrm{limb}$ to conform with the host pattern. Blocks of mesoderm from the cartilage-forming area of stage 25 or older limb buds were implanted into stage 24 or younger host limbs.

Thirty-two such operations were performed using six different donor embryos. Three of the donor embryos were stage 25, two were stage 26 and one was stage 27. The host embryos were stage 22 , stage 23 and stage 24 . Thirty of the 32 implants $(94 \%)$ developed cartilage that was clearly separate from the cartilage of the host limb (fig. 4). The two implants that failed to produce ectopic cartilage were implanted into the soft tissue area of the host limb and produced only soft tissue. One of these was from a stage 25 donor embryo, the other was from a stage 27 donor embryo. Both hosts were stage 24 .

\section{Evidence that mucopolysaccharide is synthesized in the ectopic cartilage}

It seemed possible that metachromatic material surrounding the implanted cells might not be adequate evidence that the implanted cells were cartilage cells. Traces of metachromatic material are present in the cartilage-forming area of a stage 25 limb. If a block of cartilage-forming cells is implanted into a host limb, these cells might synthesize metachromatic material during the period after the operation when the block has not yet become healed into the host limb. It has been demonstrated that the mucopolysaccharide synthesized by limb mesenchyme cells is not rapidly turned over (Searls, '67). The matrix synthesized by the cells in the implanted block prior to incorporation into the host limb would remain in the implanted block even if the host limb gained control of the implanted cells and prevented any further synthesis of matrix. The cells might appear to be cartilage cells (i.e. surrounded by metachromatic material) but no longer be acting as cartilage cells (i.e. synthesizing metachromatic material).

In order to discover if the cells in an implanted block are still synthesizing metachromatic material after incorporation into an ectopic site in a host limb, blocks of mesoderm were isolated from the cartilage-forming area of stage 25 and stage 26 limb buds. The donor embryos were not labeled with tritiated thymidine. The blocks of mesoderm were implanted in stage 24 or younger host limbs. The host embryos were allowed to develop for 46 hours at $37^{\circ}$. S-35 sulfate ( $50 \mu \mathrm{c}$; carrier-free; Oak Ridge National Laboratory; diluted with Tyrode's solution to $2.5 \mathrm{mc}$ per $\mathrm{ml}$ ) was then injected through the window onto the area vasculosa (Searls, '65). The host embryos were allowed to develop for two additional hours. The operated limbs were fixed and autoradiographs were prepared.

These operations are not listed in tables 1 and 2. The implants could not be found by histological examination unless they produced cartilage that was obviously ectopic. The implants had not been labeled prior to implanting. Thirty-one host limbs were found to contain cartilage that was obviously ectopic. The implants were obtained from six donor embryos. Five of the donors were stage 25 and 1 was stage 26 . One host was stage 21,14 were stage 22 , 6 were stage 23 and 10 were stage 24 . Where cartilage was found in these limbs, the cartilage was always heavily overlaid with silver grains (figs. 5, 6). Label in excess of background was never observed over soft tissue. It may be significant however, that the ectopic cartilage seldom was more heavily labeled than the cartilage of the host, or appeared to be at a stage of differentiation in advance of the host cartilage. This was true even when the donor embryo had been stage 26 and the host embryo was stage 22 at the time of the operation.

\section{Operations in which the donor was stage 24 or younger, the host stage 25 or older}

A block of cells obtained from the cartilage-forming area of a limb stage 24 or younger that has been implanted into a host limb stage 24 or younger generally will differentiate in conformity with the host pattern, forming soft tissue in the soft tissue area of the host limb and cartilage in the cartilage area of the host limb. It seemed of interest to discover whether this ability of the host limb to direct the differentiation of an implanted block of cells 
changes as the host limb develops. Blocks of cartilage-forming mesoderm from stage 24 or younger limbs were implanted into stage 25 or older host limbs.

Ten implants were examined in which the blocks of mesoderm had been obtained from the limbs of stage 22 embryos. None of these implants developed cartilage outside of the cartilage area of the host limb. Two of the implanted blocks intruded into the cartilage-forming area of the host limb. In these two, the implanted blocks formed both cartilage and soft tissue. The other eight implanted blocks came to lie entirely in the soft tissue area of the host limb and formed only soft tissue.

Fifteen implants were examined in which the blocks of mesoderm had been obtained from the cartilage-forming area of stage 23 embryonic limbs. Four of these implants $(27 \%)$ came to lie entirely within the soft tissue area of the host limb and produced ectopic cartilage. The other 11 implants of this group developed in accordance with the host pattern; nine came to lie entirely within the soft tissue area of the host limb and formed only soft tissue, two came to lie partially within the cartilage area and formed both cartilage and soft tissue.

Eighteen implants were examined in which the blocks of mesoderm had been obtained from the cartilage-forming area of stage 24 limbs. Fifteen of these implants $(83 \%)$ produced cartilage clearly separate from the cartilages of the host limb (fig. 7).

\section{DISCUSSION AND CONCLUSIONS}

The experiments described in this paper were done in order to determine if limb bud mesenchyme cells in the cartilageforming area of the limb ever become stabilized as cartilage, and, if they do, the stage in embryonic development when stabilization occurs. The particular criterion for "stability" used in this work was the ability of the cells to resist those influences in the limb bud that act during normal limb development to cause some limb bud mesenchyme cells to become cartilage and other limb bud mesenchyme cells to become soft tissue. The experimental procedure was to transplant blocks of cartilageforming mesenchyme from the cartilage- forming area of a limb into the area of the limb that will form soft tissue. After 48 hours of further development, the host limbs were examined to discover whether the implanted cells had differentiated according to their site of origin or according to the new environment into which they had been placed.

The effect of the stage of the host limb on the differentiation which occurred in the implants was also examined in order to discover if the influences which control the normal differentiation in the limb only act during certain stages.

The results which have been obtained can be usefully compared with the changes which have been observed histologically in the cartilage-forming area of the limb. The morphological changes which occur were first described by Fell and Canti ('34). Some of these changes have been pictured by Saunders ('48) in his depiction of the stages of limb development. The limb bud mesenchyme cells appear to be equivalent by morphological criteria (although there is a variation in cell packing through the limb) from the first appearance of the limb at about stage 17 (about 60 hours of development) until about the middle of stage 22 (about 84 hours of development, described by Fell and Canti as a leg bud about $1.0 \mathrm{~mm}$ in length). During stage 22 , the cells in the proximal half of the limb in the central core begin to become more densely packed and appear to have less cytoplasm. This area of condensed mesoderm does not show any evidence of the presence of metachromatic material. During stage 24 (about 96 hours of development, described by Fell and Canti as a leg bud of about $1.6 \mathrm{~mm}$ in length) the mass of condensed mesoderm becomes Y-shaped when viewed in frontal section. Thus the future long bones and the position of the prospective joint are demarcated at this stage, but the limbs still do not contain any metachromatic material. Traces of metachromatic material are not found in the cartilage-forming area of the limb until stage 25 (about 104 hours of development, described by Fell and Canti as a leg bud of about $2.3 \mathrm{~mm}$ in length, described by Hamburger and Hamilton ('51) as the time when the wing first becomes bent at the elbow). The metachromatic material 
in the limb increases in amount during succeeding stages until, by stage 27 (about 148 hours of development), the long bones of the limb are clearly visible as "epithelioid" cells imbedded in a lake of metachromatic material.

When blocks of limb mesenchyme cells were isolated from the cartilage-forming area of limbs prior to the appearance of metachromatic material (prior to stage 25) and implanted into the prospective soft tissue area of limb buds in which the cartilage-forming area was in the process of formation (stage 22 to stage 24), the cells generally (65 out of $70,94 \%$ ) differentiated in conformity with their new environment, forming cartilage if they had come to lie in the cartilage-forming area of the host limb and forming soft tissue if they had come to lie in the soft tissue area of the host limb. By stage 24, the cells in the cartilage-forming area of the limb have changed in their morphology, and in their rate of mucopolysaccharide synthesis (Searls, '65; Medoff, '67). Traces of metachromatic material begin to appear in the limb during stage 25 only 0 to 8 hours later. Yet even as late as stage 24, 20 out of 23 implants (83\%) differentiated in conformity with their new environment.

When blocks of limb mesenchyme cells were isolated from the cartilage-forming area of limbs after the appearance of metachromatic material (stage 25 or later) and implanted into the prospective soft tissue area of limbs in which the cartilage-forming area was in the process of formation (stage 22 to stage 24 ), the results were completely different. Cartilage formed within the implants which was clearly separate from the host cartilage in 30 out of 32 cases (94\%). Clearly a block of limb cartilage-forming cells became capable of resisting the influence of a host limb between stage 24 and stage 25 .

Experiments described in this paper demonstrate that the "stabilization" which occurs between stage 24 and stage 25 is not an artifact produced by the presence of matrix around the cells prior to the time when they are incorporated into a host limb. The cells continue to synthesize mucopolysaccharide after integration of the implanted block is complete. It is possible that the rate of synthesis of matrix may be controlled by the host $\operatorname{limb}$, the implanted cells seem to regulate to a rate of production of matrix similar to the rate in the host cartilage. However, explanations other than control by the host limb are possible.

We found no evidence for an orderly proximo-distal sequence of changes occuring over a period of time. Of the six different stage 24 donor embryos which were used for implants into stage 24 or younger hosts, only one gave any implants that developed ectopic cartilage. Eight of the 11 implants from this donor $(73 \%)$ developed in accordance with the host pattern, forming cartilage in the cartilageforming area of the host limb and soft tissue in the soft tissue area of the host limb. All 12 of the implants from the other four donors developed in accordance with the host pattern. On the other hand, of the 16 implants from three different stage 25 donor embryos, just 1 (6\%) developed in accordance with the host pattern. Since the whole of the cartilage-forming area of the donor limbs, including the girdle area, was used in these experiments, it would appear that the limb cartilage-forming area does not become stabilized in a progressive proximo-distal sequence over an extended period of time, but that the whole of the cartilage-forming area becomes stabilized at some time very close to the division between stage 24 and stage 25 . We conclude that the cells of the cartilage-forming area become stabilized as cartilage cells by this criterion at that time when the cells begin to appear morphologically to be cartilage cells.

The ability of the host limb to exert control over the differentiation of an implanted block of cells appears to decrease between stage 24 and stage 25 , but does not appear to be lost. In stage 25 or older hosts, implants from the cartilage-forming area of stage $24 \mathrm{limb}$ buds developed ectopic cartilage with about the same frequency ( $83 \%$ ) as implants from the cartilage-forming area of stage $27 \mathrm{limb}$ buds $(83 \%)$. Clearly there has been a decrease in the ability of the host limb to exert control, since only $13 \%$ of the implants from the cartilage-forming area of stage 24 limb buds formed ectopic cartilage in stage 24 or younger host limbs. However, implants 
from stage 22 limb buds conformed with the host pattern in $100 \%$ of the implants in both older and younger host limbs, indicating that older hosts have a residual ability to control the differentiation of implanted cells. The ability of the host limbs was not observed to change during any other time period examined. The hosts could validly be described as stage 24 or younger and as stage 25 or older.

The results suggest that the cells from the cartilage-forming area develop an increasingly strong chondrogenic bias as the cartilage-forming area becomes more distinct. The "stabilization" which is observed does not appear to be an abrupt change from "unstabilized" to "stabilized" but from a form unable to resist the host influences to a form which can no longer respond to the host environment. The "stability" which is observed depends on the strength of the host influences.

This result suggests that "stabilization" is not due to the appearance of a new molecule in the cartilage-forming cells at the time of stabilization. It would appear more likely that the stabilization which is observed is due to the accumulation of some "stabilizing" material. It would seem likely that accumulation short of some threshold amount can be reversed, but that accumulation beyond that threshold can not be reversed. The threshold level would appear to depend on the strength of the influences which are brought to bear on the cells. The level reached between stage 24 and stage 25 would seem to be high enough that the influences in the limb that control the differentiation of limb bud mesenchyme cells can no longer control limb bud cartilage-forming cells. Mucopolysaccharide itself would appear to be capable of playing the role of "stabilizing material," since it has been shown to accumualte in limb mesenchyme cells (Searls, '67). The mucopolysaccharide synthesizing enzymes also appear capable of playing this role as suggested by Medoff ('67). They have been shown to accumulate in the limb mesenchyme cells at the indicated time and at an appropriate rate (Medoff, '67).

We can not determine from the data presently available to us whether the "stability" which we have described in the cartilage-forming area of the limb is a property of the individual implanted cells, or a property of the block of cells. No implant, whatever the stage of the donor or of the host, produced only cartilage. In every case where there was ectopic cartilage, the cartilage was surrounded by implant cells which appear to be soft tissue. It is possible that the host limb is capable of preventing matrix synthesis by the cells on the surface of an implanted block but that the cells in the center of the implanted block are protected from host influences, and thus persist in matrix synthesis. Alternatively, the non-cartilage cells observed surrounding the ectopic cartilage could result from minor contamination of every block with some soft tissue cells from the donor limb. The only evidence we can produce against this second possibility is that we never found soft tissue in the cartilage area of the host limb. Thus we have no evidence that we ever implanted cells incapable of becoming cartilage. It is impossible to chose between these two possibilities using information now available to us.

\section{LITERATURE CITED}

Abbott, J., and H. Holtzer 1968 The loss of phenotypic traits by differentiated cells. V. The effect of 5-bromodeoxyuridine on cloned chondrocytes. Proc. Natl. Acad. Sci., U.S., 59: 1144-1151.

Patrick, J., and R. Briggs 1964 Fate of cartilage cells in limb regeneration in the Axolotl (Ambystoma mexicanum). Experientia, 20: $431-432$.

Cahn, R. D., and R. Lasher 1967 Simultaneous synthesis of DNA and specialized cellular products by differentiating cartilage cells in vitro. Proc. Natl. Acad. Sci., U.S., 58: 11311138.

Caro, L. G., and R. P. Turbergen 1962 High resolution autoradiography I. Methods. J. Cell Biol., 15: 173-188.

Coon, H. G. 1966 Clonal stability and phenotypic expression of chick cartilage cells in vitro. Proc. Natl. Acad. Sci., U.S., 55: 66-73.

Fell, H. B., and R. G. Canti 1934 Experiments on the development in vitro of the avian kneejoint. Proc. Roy. Soc., B116: 316-349.

Grobstein, C. 1964 Cytodifferentiation and its controls. Science, 143: 643-650.

Hamburger, V., and H. Hamilton 1951 A series of normal stages in the development of the chick embryo. J. Morph., 88: 49-92.

Janners, M. Y. 1968 An autoradiographic study of the growth rate of the embryonic chick wing bud. Thesis (PhD) University of Virginia, Charlottesville, Va. 
Medoff, J. 1967 Enzymatic events during cartilage differentiation in the chick embryonic limb bud. Develop. Biol., 16: 118-143.

Namenworth, M. 1968 Is cell differentiation inherited? Am. Zool., 8: 785.

Saunders, J. W., Jr, 1948 The proximo-distal sequence of origin of the parts of the chick wing and the role of the ectoderm. J. Exp. Zool., 166: 39-50.

Searls, R. L. 1965 An autoradiographic study of the uptake of $\mathrm{S}-35$ sulfate during the differ- entiation of limb bud cartilage. Develop. Biol., 11: $155-168$

- 1967 The role of cell migration in the development of the embryonic chick limb bud. J. Exp. Zool., 166: 39-45.

Steen, T. P. 1968 Stability of chondrocyte differentiation and contribution of muscle to cartilage during limb regeneration in the Axolotl (Siredon mexicanum). J. Exp. Zool., 167: 49-78.

Zwilling, E. 1959 A modified chorioallantoic grafting procedure. Trans. Bull., 6: 238-247. 


\section{PLATE 1}

\section{EXPLANATION OF FIGURES}

1 Stage 24 donor, stage 24 host. The donor embryo had been injected with $10 \mu \mathrm{c}$ of tritiated thymidine when it was stage 20. Twenty-one hours later, when the embryo had reached stage 24, the chondrogenic areas of the legs were isolated and cut into small blocks. One of these small blocks was implanted into the dorsal surface of the right wing bud of a stage 24 embryo which was then allowed to develop for 48 hours. The implanted cells formed both cartilage and soft tissue in the pattern of the host wing. Hematein. $\times 100$.

2 Stage 24 donor, stage 24 host. An implant obtained from the same donor as the implant shown in figure 1. The cartilage pattern of the host wing appears to have been distorted by the presence of the implanted cells. Hematein. $\times 100$.

3 Stage 25 donor, stage 25 host. The donor embryo had been injected with $10 \mu \mathrm{c}$ of tritiated thymidine when it was stage 22. Twenty-four hours later, when the embryo had reached stage 25, the chondrogenic areas of the legs were isolated and cut into small blocks. One of these small blocks was implanted into the dorsal surface of the wing bud of a stage 25 embryo which was then allowed to develop for 48 hours. The implanted cells formed cartilage which is clearly separate from the cartilage of the host. Hematein. $\times 100$.

4 Stage 25 donor, stage 24 host. The donor embryo had been injected with $10 \mu \mathrm{c}$ of tritiated thymidine when it was stage 22. Twenty-seven hours later, when the embryo was stage 25 , the chondrogenic areas of the legs were isolated and cut into small blocks. One of these small blocks was implanted into the dorsal surface of the wing bud of a stage 24 embryo which was then allowed to develop for 48 hours. The implanted cells formed cartilage which is next to but clearly separate from the cartilage of the host. Hematein. $\times 100$.

5 Stage 25 donor, stage 23 host. The chondrogenic areas of the leg buds of a stage 25 embryo were isolated, cut into small blocks, and implanted into the dorsal surface of the right wing bud of a stage 23 embryo. Forty-six hours later, $50 \mu \mathrm{c}$ of carrier-free S-35 sulfate were injected into the host egg onto the area vasculosa. Two hours after the injection, the host wing was fixed and autoradiographs prepared using Ilford L-4 emulsion. The emulsion was developed after three weeks, the sections stained and examined for the presence of ectopic cartilage. This section shows ectopic cartilage near to but separate from the cartilage of the host wing. Toluidine blue, $\times 100$.

6 A section which is six serial sections away from the section shown in figure 5. Stained with hematein and photographed in dark field to show the distribution of the silver grains. $\times 100$.

7 Stage 24 donor, stage 25 host. The donor embryo had been injected with $5 \mu \mathrm{c}$ of tritiated thymidine when it was stage 22 . Twenty-one hours later, when the embryo was stage 24, the chondrogenic areas of the leg buds were isolated and cut into small blocks. One of these small blocks was implanted into the dorsal surface of the wing bud of a stage 25 embryo which was then allowed to develop for 48 hours. The implanted cells formed cartilage which is clearly separate from the cartilages of the host. Hematein. $\times 100$. 

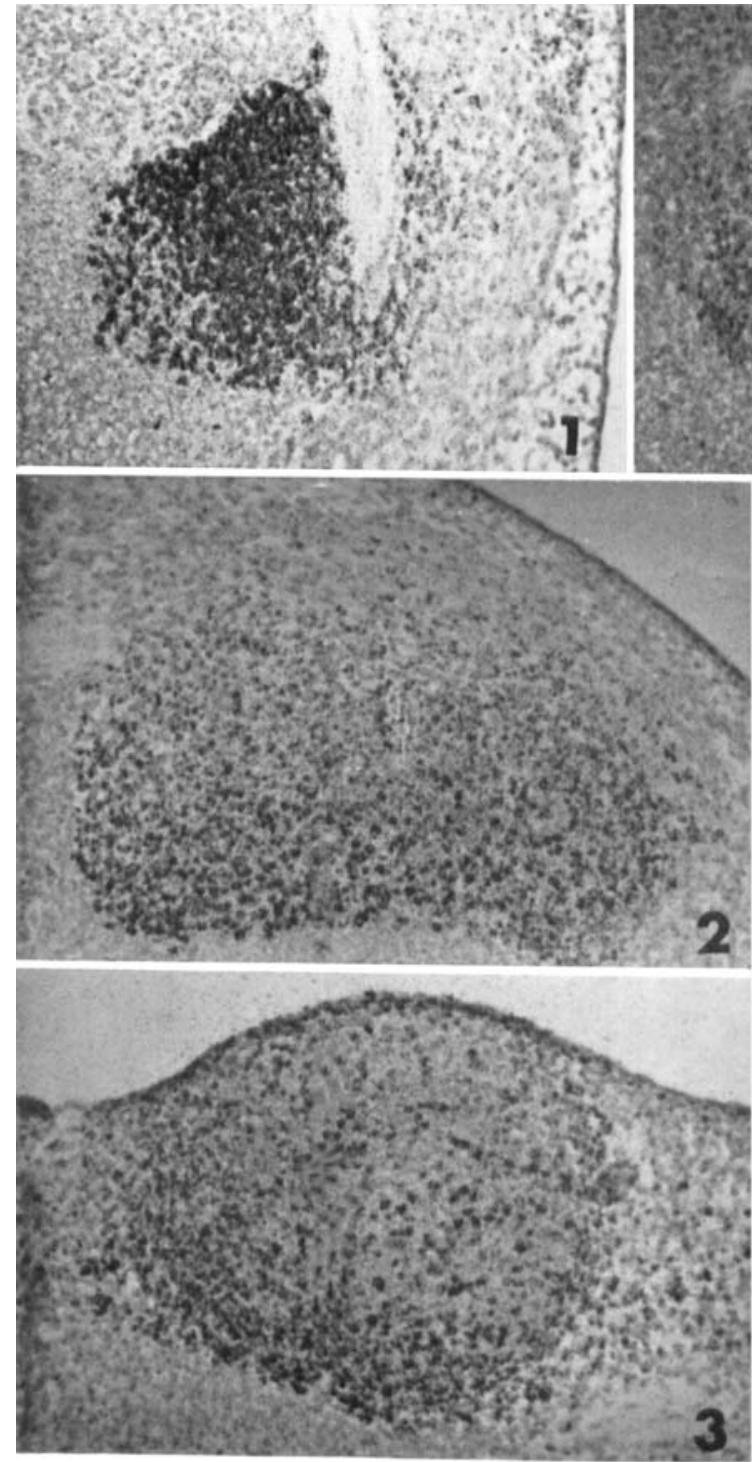
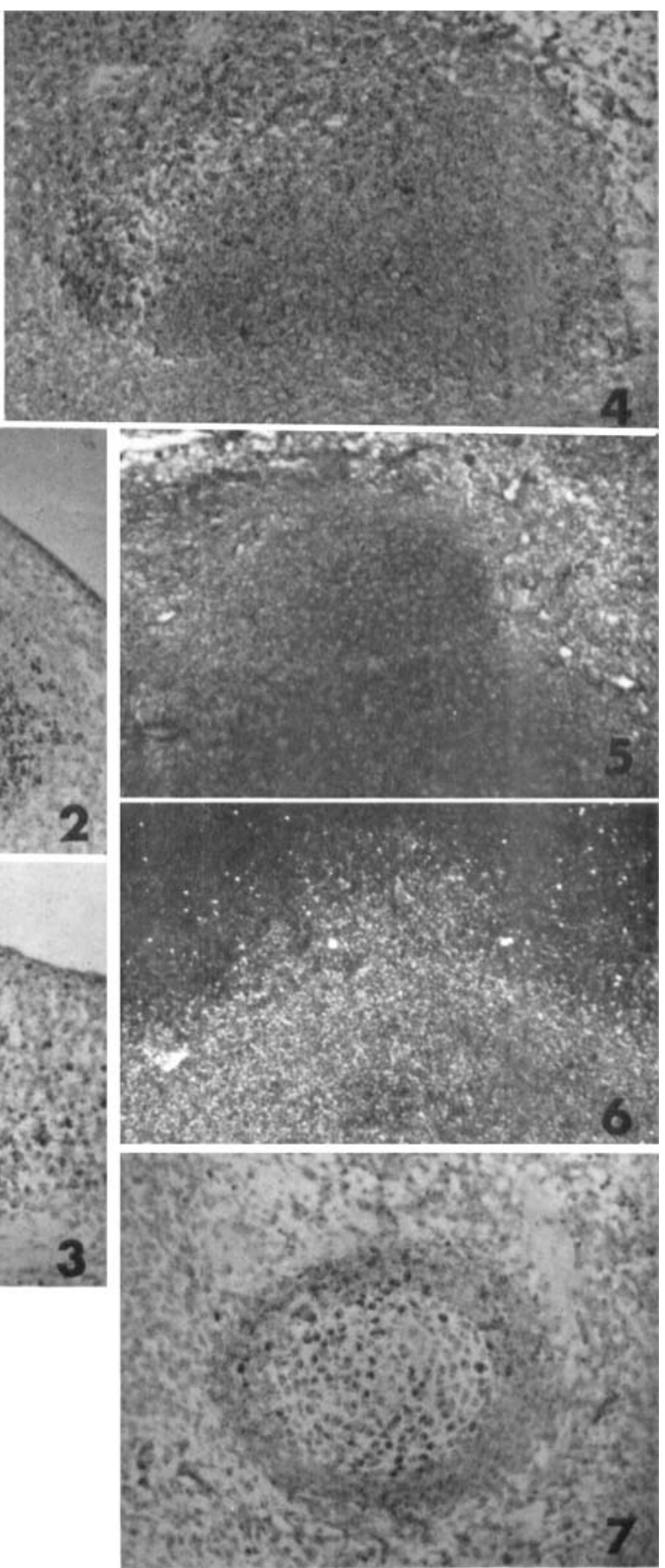